\title{
Percepção Ambiental da População da Cidade da Lapa - PR em relação ao Parque Estadual do Monge
}

\author{
Environmental Perception of the Population of Lapa - Paraná, Brazil regarding \\ Monge State Park
}

\author{
Percepción Ambiental de la Población de la Ciudad de Lapa - PR en relación al \\ Parque Estadual del Monje
}

\author{
Mariana Meira Micaloski ${ }^{1}$ \\ Ronaldo Viana Soares ${ }^{2}$ \\ Alexandre França Tetto ${ }^{3}$
}

RESUMO: Estudos de percepção ambiental contribuem para a utilização mais racional dos recursos naturais. Tais estudos têm importância para uma melhor compreensão da inter-relação entre o homem e o ambiente, sendo que uma das maiores dificuldades na proteção dos ecossistemas está na existência de diferentes percepções dos valores e da importância entre os indivíduos de culturas diferentes. O presente trabalho teve como objetivo caracterizar a percepção ambiental da população da cidade da Lapa em relação ao Parque Estadual do Monge, por meio da aplicação de questionários. Foram aplicados 96 questionários, tanto em dias da semana como no final de semana em duas ruas principais da cidade. Os resultados mostraram que $63,27 \%$ dos entrevistados não sabiam o que é uma unidade de conservação. Apesar de o município possuir quatro unidades de conservação, 69,39\% não sabem da existência de tais áreas na cidade. Em relação ao Parque do Monge, $48 \%$ dos entrevistados afirmaram não saber qual é seu objetivo, e dos $52 \%$ que responderam saber qual o objetivo do parque, $22 \%$ afirmaram que a unidade tinha como única finalidade o turismo na cidade. Os dados obtidos mostraram o pouco entendimento da população sobre questões relacionadas à unidades de conservação e ao Parque Estadual do Monge.

PALAVRAS-CHAVE: Unidade de conservação; Proteção integral; Conservação da natureza.

\footnotetext{
${ }^{1}$ Engenheira Florestal, mestranda em Engenharia Florestal na Universidade Federal do Paraná. Endereço: Rua João Mendes da Silveira, 146, Pinheirinho, Curitiba, Paraná, CEP: 81150-260. E-mail: marianamicaloski@hotmail.com.

${ }^{2}$ Engenheiro Florestal, professor doutor do Departamento de Ciências Florestais da Universidade Federal do Paraná. Endereço: Av. Pref. Lothário Meissner, 632, Jardim Botânico, Curitiba, Paraná, CEP: 80210-170. E-mail: rvsoares@ufpr.br.

${ }^{3}$ Engenheiro Florestal, professor doutor do Departamento de Ciências Florestais da Universidade Federal do Paraná. Endereço: Av. Pref. Lothário Meissner, 632, Jardim Botânico, Curitiba, Paraná, CEP: 80210-170. E-mail: tetto@ufpr.br.
} 


\begin{abstract}
Studies of environmental perception contribute to a more rational use of natural resources. Such studies are important for a better understanding of the interaction between man and the environment, and one of the greatest difficulties in protecting ecosystems is the existence of different perceptions of their value and importance among individuals from different cultures. The present study aimed to characterize environmental perception of the population of the city of Lapa regarding the Monge State Park, through the application of questionnaires. The results showed that $63.27 \%$ of those interviewed did not know what a conservation unit is. Although the municipality has four conservation units, $69.39 \%$ are unaware of the existence of such areas in the city. Regarding Monge Park, $48 \%$ of respondents stated that they did not know what the park's objective was, and among the $52 \%$ who answered that they knew the park's purpose, $22 \%$ said that this conservation unit had tourism as its only purpose in the city. Data obtained shows poor understanding of the population on issues related to conservation units and the Monge State Park.
\end{abstract}

KEYWORDS: Conservation unit; Full protection; Nature conservation.

RESUMEN: Los estudios de percepción ambiental contribuyen a la utilización más racional de los recursos naturales. Tales estudios tienen importancia para una mayor comprensión de la interrelación entre el hombre y el ambiente, siendo que una de las mayores dificultades en la protección de los ecosistemas está en la existencia de diferentes percepciones de los valores y de la importancia entre los individuos de culturas diferentes. El presente trabajo tuvo como objetivo caracterizar la percepción ambiental de la población de la ciudad de Lapa en relación al Parque Estadual del Monje, por medio de la aplicación de cuestionarios. Se aplicaron 96 cuestionarios, tanto en días de la semana como en el fin de semana en dos calles principales de la ciudad. Los resultados mostraron que el $63,27 \%$ de los entrevistados no sabían lo que es una unidad de conservación. Aunque el municipio posee cuatro unidades de conservación, el 69,39\% no sabe de la existencia de tales áreas en la ciudad. En cuanto al Parque del Monje, el $48 \%$ de los encuestados afirmó no saber cuál es su objetivo, y del $52 \%$ que respondieron a saber cuál es el objetivo del parque, el 22\% afirmó que la unidad tenía como única finalidad el turismo en la ciudad. Los datos obtenidos mostraron el poco entendimiento de la población sobre cuestiones relacionadas a unidades de conservación y al Parque Estadual del Monje.

PALABRAS CLAVES: Unidad de conservación; Protección integral; Conservación de la naturaleza.

\title{
INTRODUÇÃO
}

A palavra percepção é derivada do latim perceptio, que significa "compreensão, faculdade de perceber". Esse termo também é entendido como o ato ou efeito de perceber, combinação dos sentidos no reconhecimento de um objeto, recepção de um estímulo, faculdade de conhecer independentemente dos sentidos, sensação, intuição, ideia, imagem ou representação intelectual (MARIN; TORRES; COMAR, 2008). Segundo Okamoto (2002, p. 58), as pessoas enxergam e reconhecem aquilo de seu interesse, conforme seus pensamentos, sendo a realidade restrita a esta perspectiva e a mente seletiva. Sendo assim, a percepção varia de acordo com os sentidos, o grupo e o indivíduo.

Cada indivíduo percebe, reage e responde diferentemente às ações sobre o ambiente em que vive, as respostas daí decorrentes são resultados das percepções, dos processos 
cognitivos, julgamentos e expectativas de cada pessoa. Sendo assim, a percepção ambiental pode ser definida como a tomada de consciência do ambiente pelo homem, ou seja, perceber o ambiente em que está inserido (FERNANDES et al., 2004).

Para estes mesmos autores, o estudo da percepção ambiental é de fundamental importância para compreender melhor a inter-relação entre o homem e o ambiente, suas expectativas, anseios, satisfações, julgamentos e condutas. A importância desse tipo de estudo também foi ressaltada pela UNESCO (1973), para a qual uma das principais dificuldades na proteção dos ecossistemas naturais está na existência de diferentes percepções dos valores e da importância entre os indivíduos de culturas diferentes.

Projetos de percepção ambiental contribuem para a utilização mais racional dos recursos naturais (WHYTE, 1978), tendo em vista que quando o ser humano reflete sobre essa relação, procura o entendimento de suas percepções e se questiona sobre seu lugar, torna possível a avaliação de suas ações no ambiente (MARIN; TORRES; COMAR, 2003). O presente trabalho teve como objetivo caracterizar a percepção ambiental da população da cidade da Lapa em relação ao Parque Estadual do Monge.

\section{MATERIAL E MÉTODOS}

\section{Área de Estudo}

O Parque Estadual do Monge (PEM) está localizado na cidade da Lapa, uma das cidades mais antigas do estado do Paraná, que teve sua origem ligada ao tropeirismo, quando a cidade era usada como "pouso" dos tropeiros ao longo da "Estrada da Mata", que fazia parte do Caminho do Viamão, estrada que ligava o Rio Grande do Sul a Sorocaba, em São Paulo (IAP, 2002).

O município da Lapa está localizado na porção sudeste do estado do Paraná, região metropolitana de Curitiba, a 62,8 quilômetros de distância da capital do Estado. Sua área territorial corresponde a 2.097,751 quilômetros quadrados, com uma população estimada de 47.557 habitantes, sendo que $60,6 \%$ dos habitantes correspondem à população urbana (IPARDES, 2016).

A cidade está localizada na região geográfica do Segundo Planalto, apresentando um relevo acidentado a ondulado, sendo abrangida por rochas sedimentares permocarboníferas do Grupo Itararé. A vegetação da região é classificada como campestre, e predominantemente denominada Estepe Gramíneo-lenhosa. A área possui diversas 
tipologias vegetais primárias e secundárias típicas do planalto meridional e da Floresta Ombrófila Mista (IAP, 2002).

Seu clima é classificado como subtropical com as estações do ano bem definidas, sendo que suas temperaturas médias variam de $8,9^{\circ} \mathrm{C}$ nos meses mais frios a $26,5^{\circ} \mathrm{C}$ nos meses mais quentes; sua precipitação anual pode variar de 1400 a 1600 milímetros, e a umidade relativa do ar do município não apresenta grandes oscilações durante o ano, possuindo um valor médio de $82 \%$, podendo variar de $78 \%$ nos meses de agosto, novembro e dezembro a $85 \%$ em março e junho (MARIN, 2002).

O Parque Estadual do Monge foi criado a partir da Lei no 4.170, de 22 de fevereiro de 1960, e está localizado a 3 quilômetros de distância da sede da cidade da Lapa (Figura 1). O parque se encontra em uma área de transição entre o Primeiro e o Segundo Planalto e possui uma área total de 297,83 hectares. Inserido na bacia hidrográfica do rio Iguaçu, o parque, por situar-se em local topograficamente elevado, protege diversas nascentes e pequenos riachos, os quais desaguam no rio Estiva, um dos tributários do rio da Várzea, um dos principais afluentes do rio Iguaçu (IAP, 2002).

Figura 1 - Localização do Parque Estadual do Monge
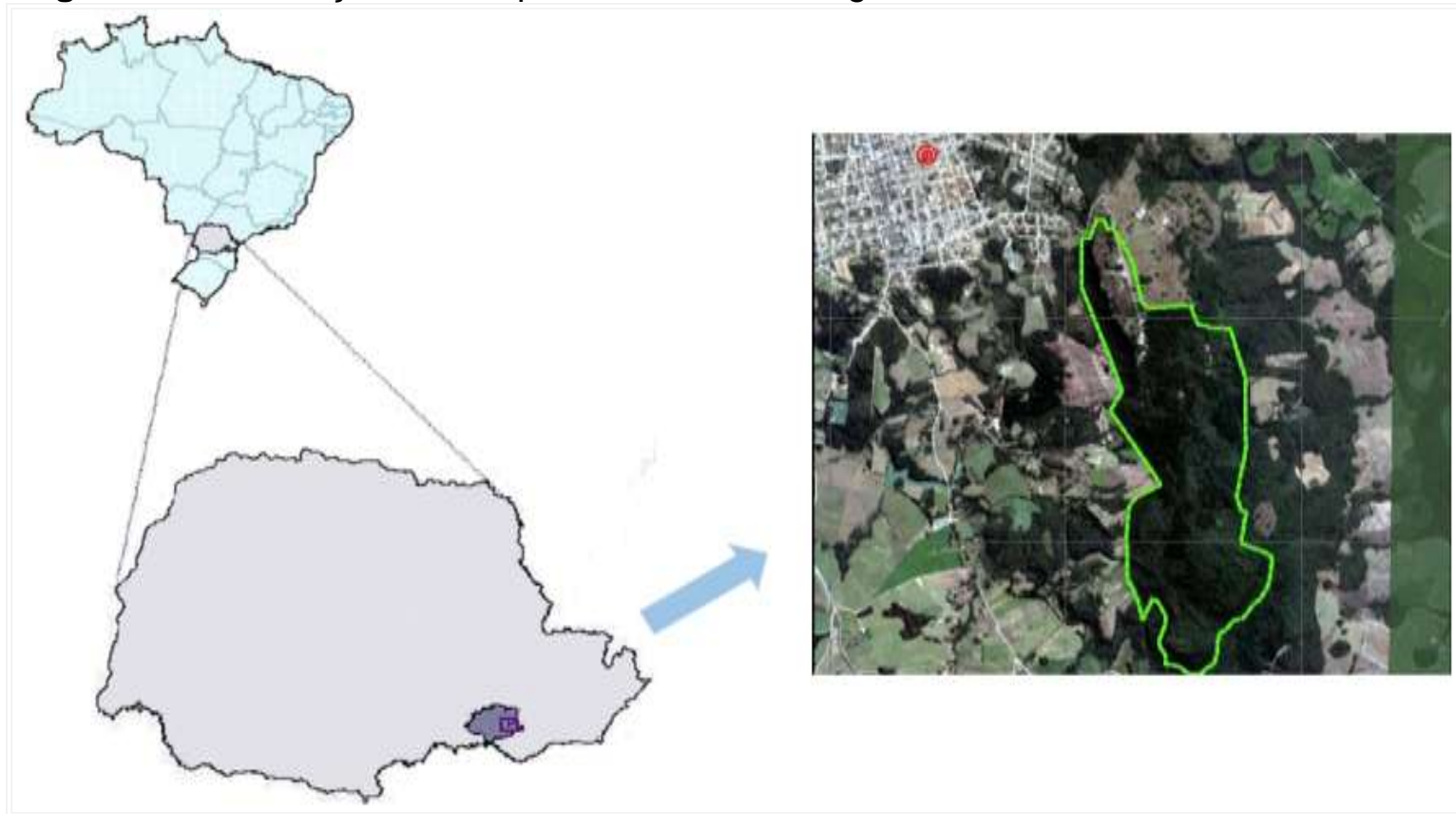

Fonte: Adaptado pelos autores de Hornung (2007).

Recebeu este nome por possuir uma gruta que, entre 1847 e 1855, teria servido de abrigo a um monge ermitão, o monge João Maria d' Agostini. Imigrante italiano que veio ao Brasil em 1844, João Maria d' Agostini teria sido um frei da ordem de Santo Agostinho, que pregava na Matriz da Lapa por volta dos anos de 1840. Como prática apostólica, percorria 
os estados do sul a fim de espalhar o bem, orientando e receitando ervas medicinais às pessoas que o procuravam. Devido à sua prática, os caboclos lhe atribuíram curas milagrosas e passaram a chamá-lo de "São João Maria". O monge São João Maria se abrigou na região onde foi criado o parque e se dedicou ao estudo das plantas do local, fazendo orações públicas e medicando os enfermos, tornando-se um líder religioso, atraindo habitantes de todos os arredores que acreditavam que o monge era milagreiro. Por estas histórias, o parque ficou conhecido devido à Gruta do Monge e à uma fonte existente no local, a qual se acredita ser milagrosa, o que faz com que atraia um grande número de romeiros movidos pela fé (IAP, 2002).

\section{Obtenção e análise de dados}

A análise da percepção ambiental da população lapeana em relação ao Parque Estadual do Monge foi feita por meio da aplicação de questionários, que foram divididos em duas partes: i. a primeira abordava três perguntas para traçar o perfil dos entrevistados (idade, escolaridade e renda pessoal mensal); ii. a segunda continha perguntas relacionadas à percepção ambiental da população em relação ao parque, sendo perguntado se sabiam o que era uma Unidade de Conservação (UC), se já haviam visitado alguma UC, se sabiam da existência de alguma UC na cidade da Lapa, se já haviam visitado o Parque Estadual do Monge (PEM), se sabiam o objetivo do PEM, se tinham conhecimento de restrições ao uso e acesso ao parque, da existência de um Conselho Consultivo e da existência de algum programa desenvolvido entre o parque e a comunidade da Lapa, quem deveria cuidar do parque, se já teve participação na tomada de decisões em relação ao parque e qual o elemento de maior valor no PEM.

Após a realização de cada entrevista, foi entregue aos entrevistados um pequeno informativo sobre o Parque Estadual do Monge, o qual apresentava sua história e respondia todas as perguntas do questionário.

Objetivando um nível de confiança de 95\% e um erro amostral de 10\%, foram aplicados 96 questionários nos dias 20 a 29 de julho de 2016, sendo aplicados tanto em dias da semana quanto no final de semana, buscando atingir tanto a população urbana quanto a rural do município, tendo em vista que nos finais de semana a população rural tem o costume de se deslocar até à cidade. Os questionários foram aplicados em duas ruas principais da cidade da Lapa, Avenida Dr. Manoel Pedro e Rua Barão do Rio Branco, que concentram vários comércios e bancos. 
Tomando como base o estudo realizado por Vilanova, Chichorro e Arruda (2010), para a análise da faixa etária dos entrevistados foram estabelecidas seis classes, sendo elas: menores de 20 anos, de 20 a 29 anos, de 30 a 39 anos, de 40 a 49 anos, de 50 a 59 anos e 60 anos ou mais. De acordo com o grau de instrução, as classes estabelecidas foram: ensino fundamental completo e incompleto, ensino médio completo e incompleto, ensino superior completo e incompleto e pós-graduação completa e incompleta. Para análise da renda pessoal estabeleceu-se as seguintes classes: nenhuma renda, até um salário mínimo, maior que um a três salários mínimos, maior que três a cinco salários mínimos, maior que cinco a sete salários mínimos, maior que sete a 10 salários mínimos e maior que 10 salários mínimos.

A maioria das perguntas dos questionários foi aberta, permitindo uma liberdade para que o entrevistado abordasse o assunto sob seu ponto de vista e, para uma melhor análise, os dados obtidos foram categorizados, o que consiste em agrupar dados considerados comuns (MORAES, 1999), por exemplo, respostas como "um lugar para passear" e "local de visitação" foram tabuladas na categoria de "turismo". Após a categorização das respostas, os dados foram tabulados em planilha eletrônica Excel para análise.

\section{RESULTADOS E DISCUSSÃO}

A primeira parte do questionário objetivava traçar o perfil socioeconômico dos entrevistados, referente a faixa etária, renda pessoal e nível de escolaridade. Em relação à faixa etária dos entrevistados, como mostra a Figura 2, houve uma maior representatividade da classe de 20 a 29 anos, correspondendo a 35,7\%, e uma menor representatividade da classe de menores de 20 anos, representada por $9,2 \%$ dos entrevistados.

Com relação ao nível de escolaridade dos entrevistados, os resultados mostraram que 65,3\% completou o ensino básico obrigatório (educação infantil, ensino fundamental e ensino médio), sendo que, destes, $31,6 \%$ possuem escolaridade até o ensino médio completo; e $34,7 \%$ dos entrevistados cursaram ou estão cursando o ensino superior (Figura 3). Na descrição dos entrevistados conforme sua renda pessoal (Tabela 1), a categoria maior que um a três salários mínimos foi a que teve maior representatividade (30,61\%).

As outras perguntas do questionário tinham como objetivo analisar a percepção ambiental da população em relação ao Parque Estadual do Monge. Quando questionados se sabiam o que é uma unidade de conservação, 36,73\% dos entrevistados responderam que sim, porém, destes, $41,7 \%$ não a conceituaram corretamente, sendo que suas respostas variavam de que uma UC era o "centro histórico da cidade da Lapa e as fachadas tombadas pelo patrimônio histórico" aos "plantios de Pinus" que há na região. Ao fazer uma 
relação entre a escolaridade e o conhecimento sobre o que seria uma UC (Figura 4), se observou que, de maneira geral, quanto maior o nível de escolaridade dos entrevistados maior é o entendimento do que é uma unidade de conservação.

Figura 2 - Distribuição por classes de idade dos entrevistados

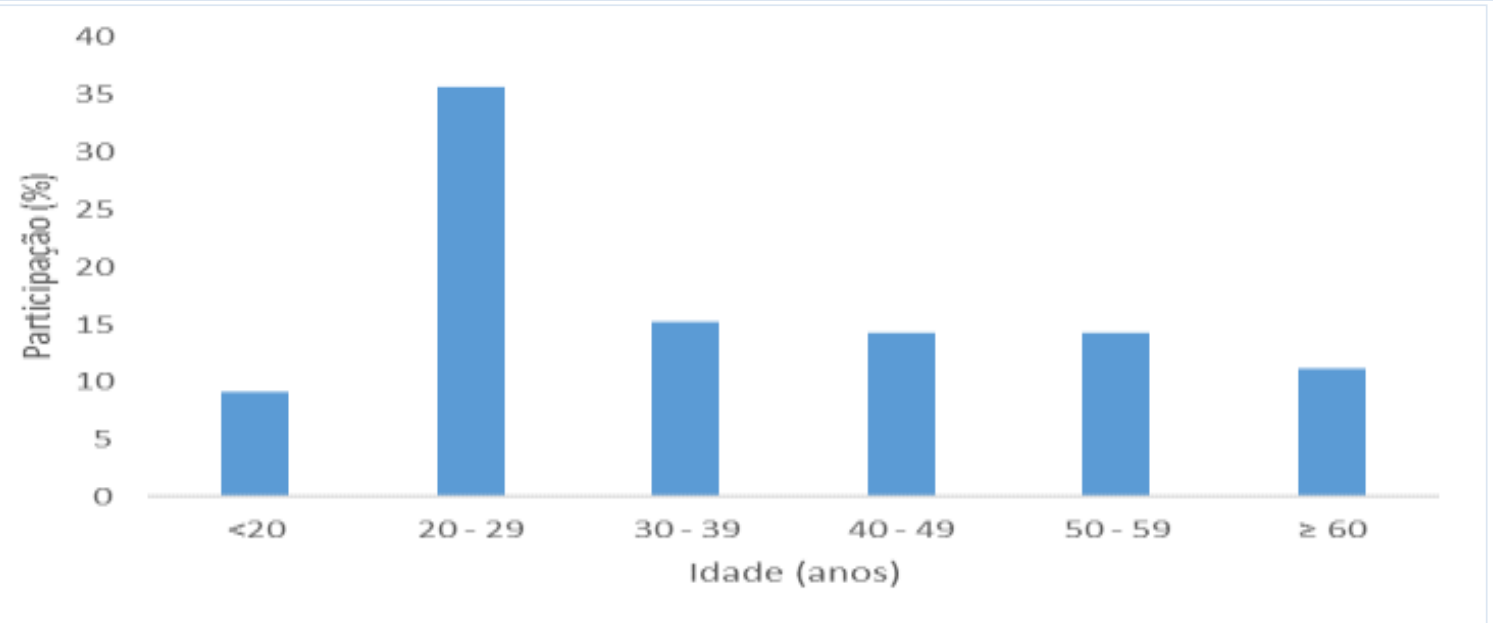

Fonte: os autores.

Figura 3 - Nível de escolaridade dos entrevistados

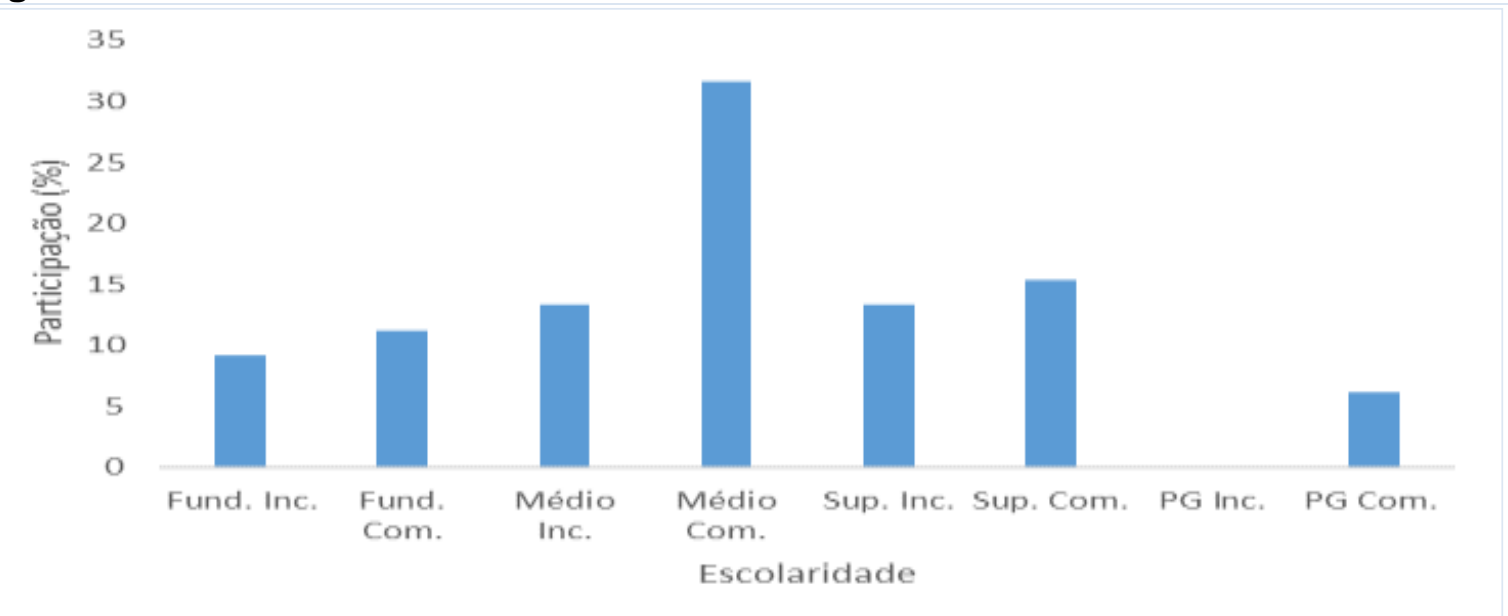

Fonte: os autores.

A cidade da Lapa possui quatro unidades de conservação: a APA da Escarpa Devoniana, a Floresta Estadual do Passa Dois, o Parque Estadual do Monge e a Reserva Particular do Patrimônio Natural Mata do Uru (IAP, 2002). Indagados sobre a existência de unidades de conservação na cidade, 69,39\% dos entrevistados responderam que não havia nenhuma no município e 30,61\% citaram o Parque do Monge como única unidade de conservação da região. O mesmo pode se observar no estudo realizado por Silva e Silva (2013) com a comunidade do entorno do Parque Natural Municipal Barão de Mauá, no 
município de Magé, no Rio de Janeiro, no qual $85 \%$ das pessoas responderam que não conheciam unidades de conservação no município. O resultado, segundo o autor, reflete a distância que existe entre o assunto e a população.

Tabela 1 - Renda pessoal mensal dos entrevistados

\begin{tabular}{lc}
\hline \multicolumn{1}{c}{ Renda pessoal (salário mínimo) } & (\%) \\
\hline Nenhuma & 9,18 \\
Até 1 $(\mathrm{R} \$ 880,00)$ & 19,39 \\
Maior que 1 a 3 $(\mathrm{R} \$ 880,01$ a $\mathrm{R} \$ 2.640,00)$ & 30,61 \\
Maior que 3 a 5 $(\mathrm{R} \$ 2.640,01$ a $\mathrm{R} \$ 4.400,00)$ & 28,57 \\
Maior que 5 a 7 $(\mathrm{R} \$ 4.400,01$ a $\mathrm{R} \$ 6.160,00)$ & 10,21 \\
Maior que 7 a $10(\mathrm{R} \$ 6.160,01$ a $\mathrm{R} \$ 8.800,00)$ & 1,02 \\
Acima de $10(\mathrm{R} \$ 8.800,01$ ou mais) & 1,02
\end{tabular}

Figura 4 - Entendimento sobre UCs conforme escolaridade

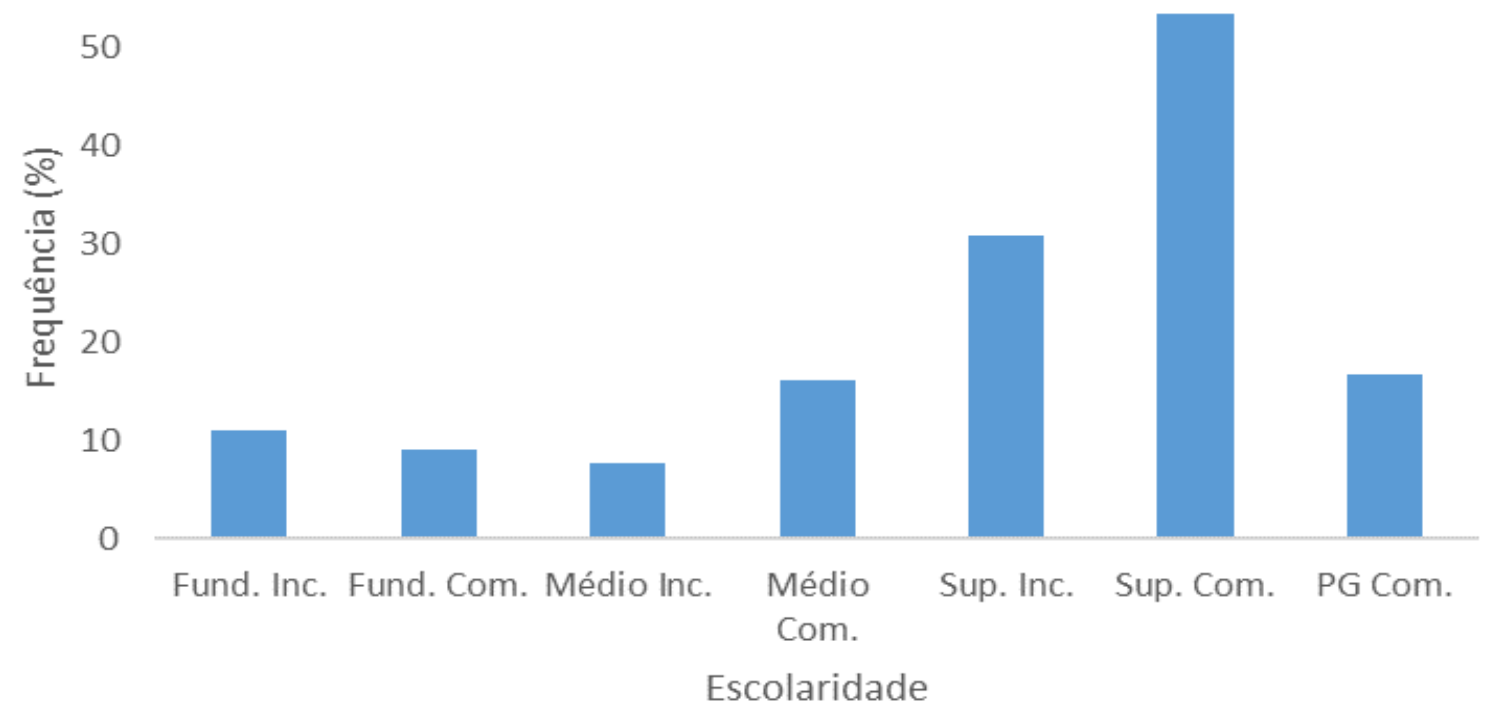

Fonte: Os autores. Nota: a classe pós-graduação incompleta, por não ter tido representatividade nos questionários, não foi considerada nesta análise.

Dos entrevistados, 92,68\% já visitaram o Parque do Monge, sendo que 51\% visitam o local anualmente (Figura 5). Pôde-se observar também, durante as entrevistas, que parte da população não tem conhecimento de que o parque está aberto, tendo em vista que ficou fechado de 2009 a 2012 para revitalização.

O Parque Estadual do Monge é uma unidade de conservação de proteção integral e tem como objetivo preservar a natureza permitindo o uso indireto de seus recursos naturais, ou seja, na área é permitido apenas pesquisa científica, educação ambiental, interpretação ambiental e turismo. Quanto ao objetivo do parque, $48 \%$ responderam que não sabiam qual 
o propósito da área, dos $52 \%$ que responderam que sabia qual era o objetivo do parque, $22 \%$ afirmaram que a unidade tinha como única finalidade o turismo (Figura 6).

Figura 5 - Frequência de visitação da população ao Parque Estadual do Monge

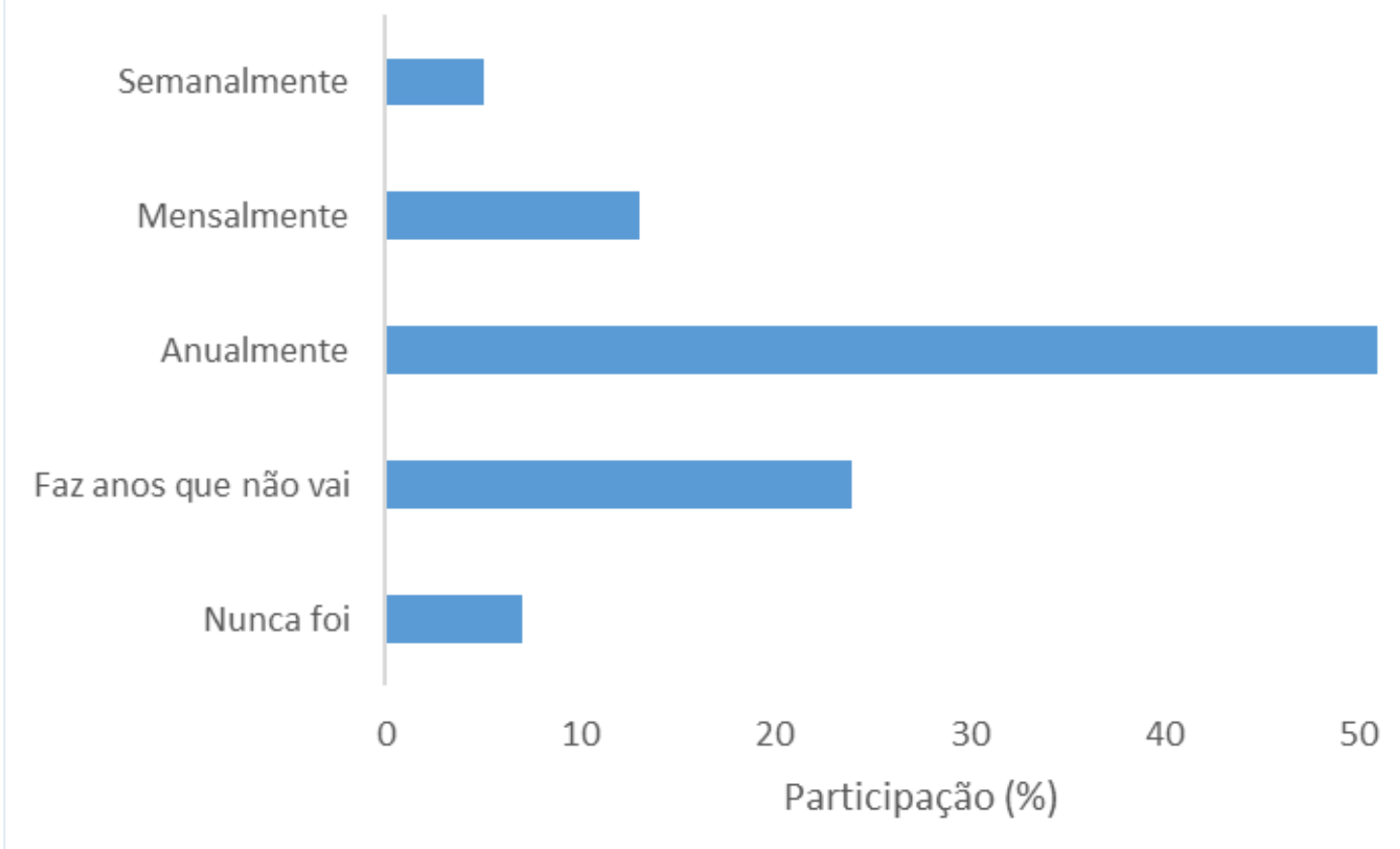

Fonte: os autores.

Figura 6 - Respostas em relação ao objetivo do Parque Estadual do Monge

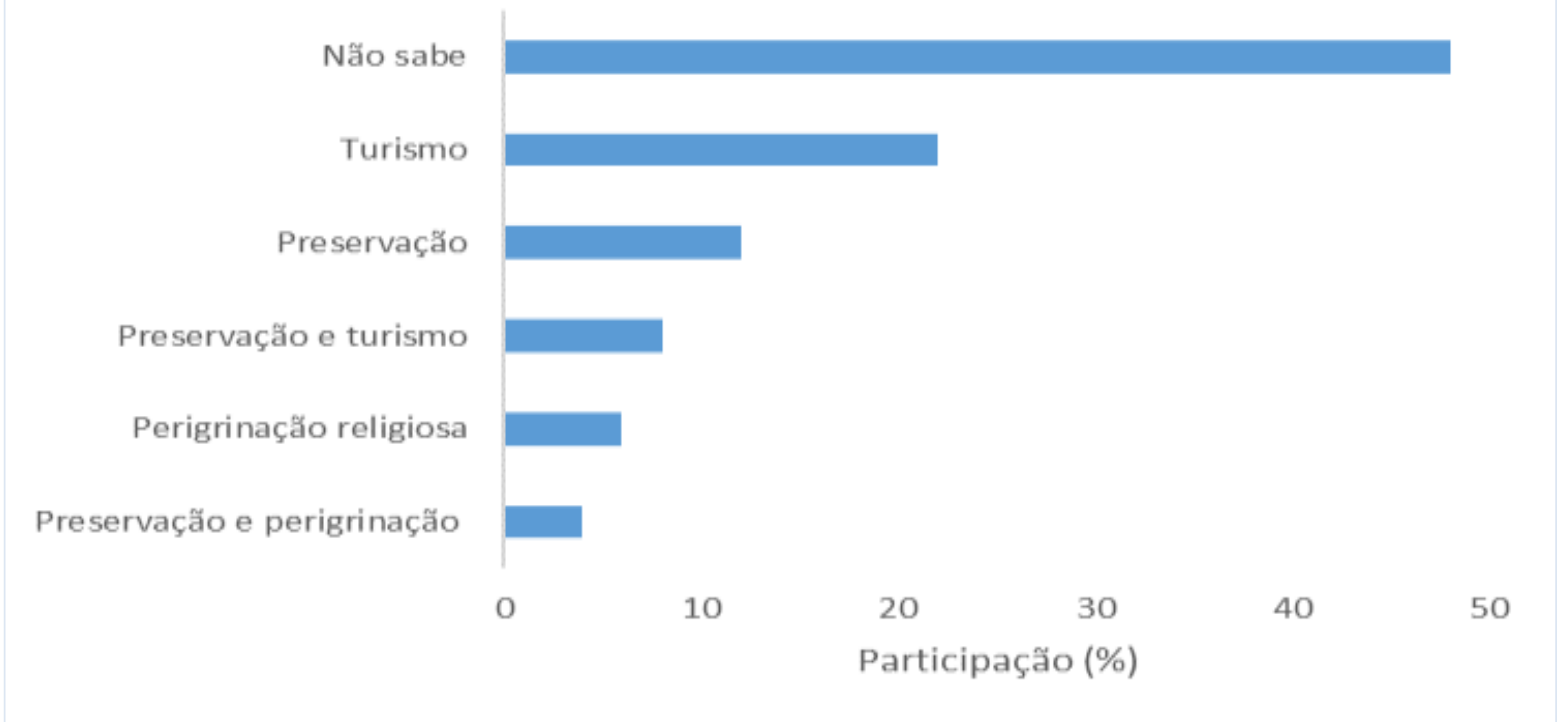

Fonte: os autores.

Quanto às possíveis restrições de uso e acesso ao parque, 55,1\% declararam não saber sobre a existência de restrições, dos $44,9 \%$ que afirmaram saber, $61,36 \%$ citaram a 
restrição de horários para entrada no parque, além da proibição de acesso ao local com automóveis e bicicletas. Em relação ao Parque Natural Municipal Barão de Mauá - RJ, 73\% dos entrevistados declararam não saber de restrições ao uso e acesso ao parque (SILVA; SILVA, 2013).

Segundo a Lei do SNUC, todas as unidades de conservação do grupo de proteção integral devem dispor de um Conselho Consultivo, que tem como função auxiliar o chefe da UC na sua gestão e integrá-la à população. Este conselho deve ser presidido pelo órgão responsável pela administração da unidade e também deve ser formado por representantes de órgão públicos e da população (BRASIL, 2000). Este assunto foi abordado por meio da seguinte pergunta: "Você sabe da existência de um Conselho Consultivo do Parque Estadual do Monge e quem o compõe?", 97,96\% responderam que não sabiam da existência de um conselho; os que responderam que possuíam conhecimento sobre tal não souberam responder quem o compunha.

Considerando o fato de que dentro do Conselho Consultivo deve haver representação da população, indagou-se aos entrevistados se já haviam participado da tomada de decisão em relação ao parque e 2,04\% responderam que já haviam participado de alguma reunião do Conselho Consultivo do parque.

No plano de manejo do Parque Estadual do Monge há o programa de uso público, o qual tem como objetivo ordenar, orientar e direcionar o uso da unidade de conservação pelo público (IAP, 2002). Neste programa há a designação de três subprogramas: a) recreação e interpretação ambiental; b) educação ambiental; e c) concessões. Estes subprogramas, em suas atividades e normas, preveem o envolvimento da comunidade da cidade da Lapa com a gestão do parque, visando uma melhor interação e entendimento da população com a unidade. Tendo isto em vista, foi questionado aos entrevistados se sabiam da existência de algum programa desenvolvido entre o parque e a comunidade da Lapa, e 96,94\% respondeu que não sabiam da existência de nenhum programa, os 3,06\% que tinham conhecimento comentaram sobre trabalhos voluntários da população para restaurar alguns ambientes do parque, como o Cristo, mas nada foi comentado sobre programas desenvolvidos entre o órgão gestor e a população.

O Parque do Monge, por ser uma unidade de conservação estadual, é gerido pelo órgão ambiental do estado do Paraná, o Instituto Ambiental do Paraná (IAP). Indagados sobre quem deve administrar o parque, a população ficou dividida entre prefeitura, estado e população, como mostra a Figura 7 , sendo que quando se referiam à administração sob a reponsabilidade da população imaginavam uma ONG ou um órgão formado pela comunidade e que não envolvesse questões políticas. 
Figura 7 - Respostas dos entrevistados sobre quem deve administrar o Parque Estadual do Monge

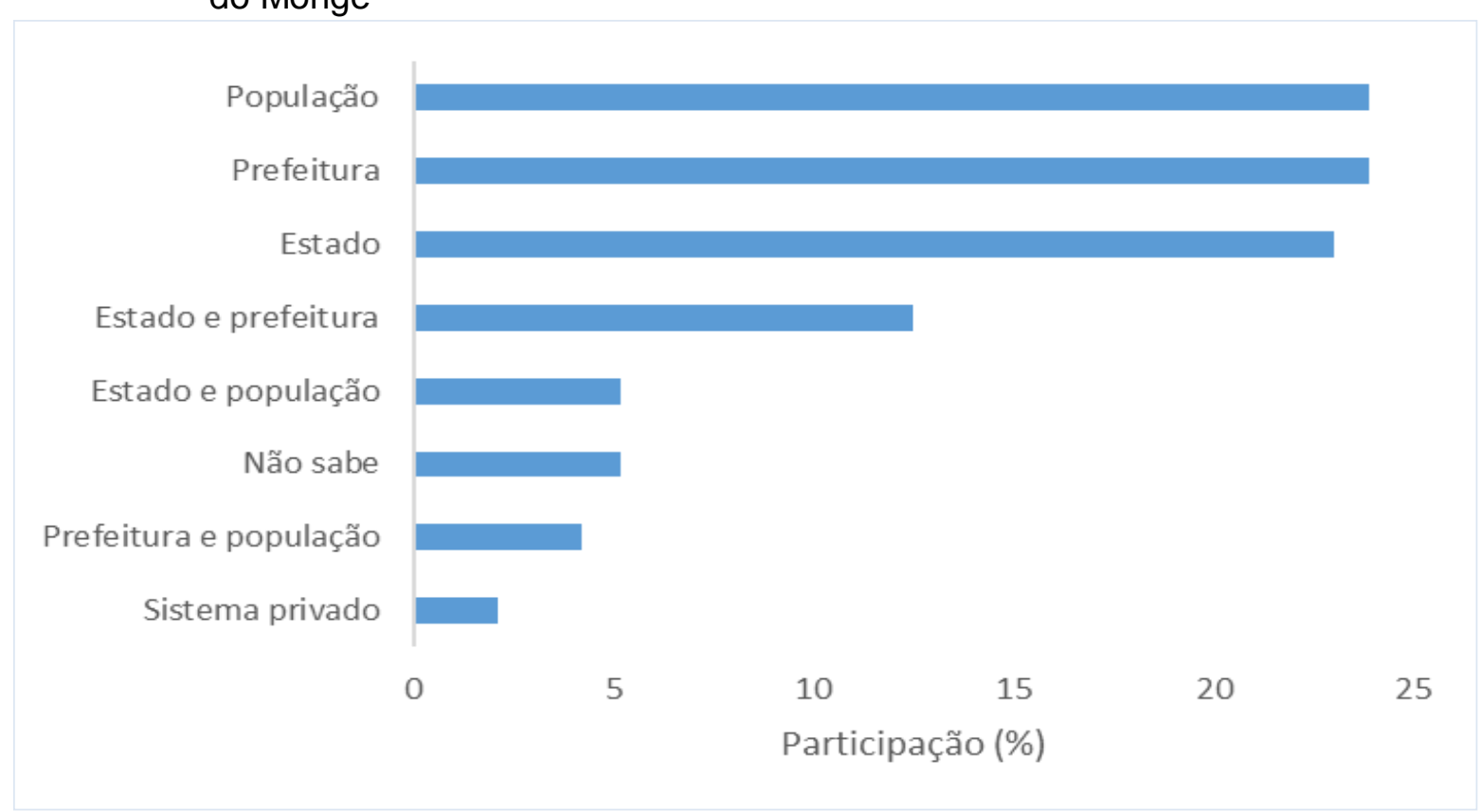

Fonte: os autores.

O parque é dotado de estruturas turísticas, como o mirante com vista para a cidade da Lapa, o Cristo, estátua instalada no parque como agradecimento a devoção da população, além de possuir uma natureza exuberante pela sua conservação. Dos entrevistados $62,75 \%$ consideraram a natureza como sendo o elemento de maior valor do parque, seguido pelas estruturas turísticas com 20,59\% (Figura 8).

Figura 8 - Respostas sobre elemento de maior valor no Parque Estadual do Monge

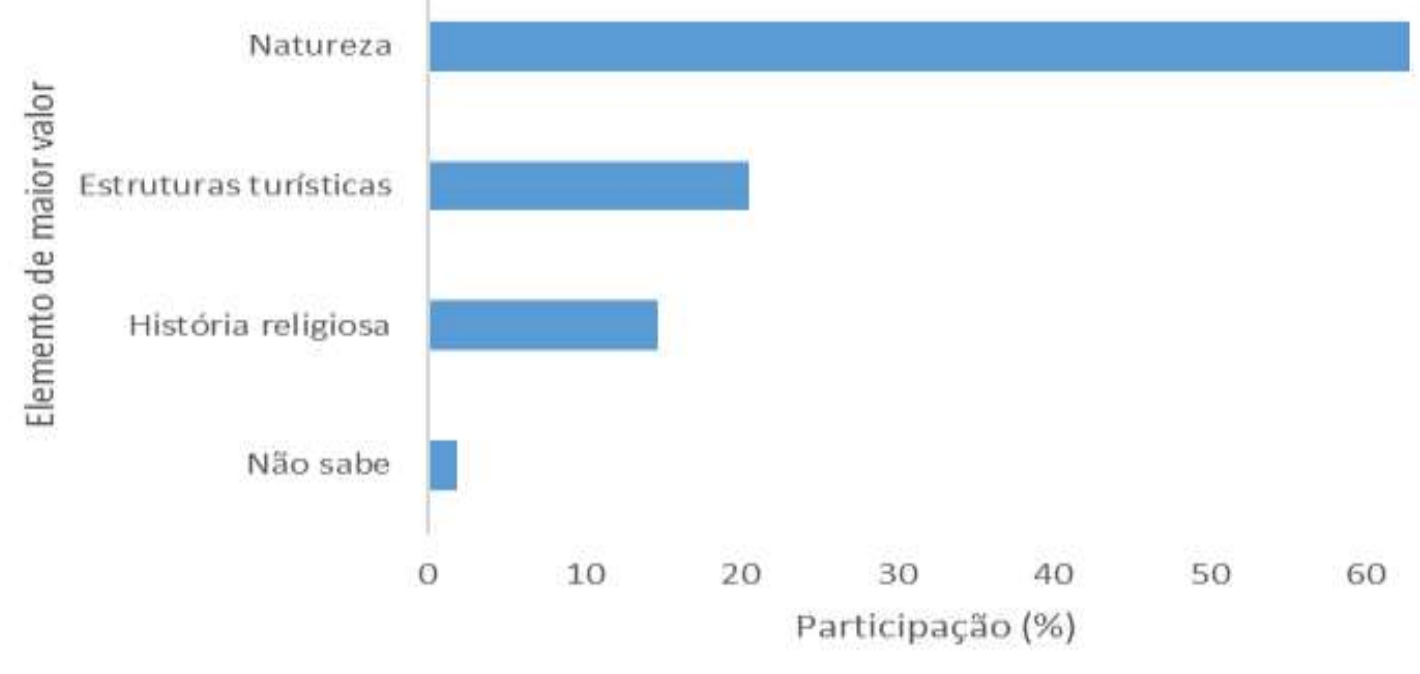

Fonte: os autores. 
Quando relacionadas às respostas da questão de qual seria o elemento de maior valor com a faixa etária dos entrevistados (Figura 9), notou-se que a classe de menores de 20 anos foi a mais representativa em relação a considerar a natureza como principal elemento, seguido da classe de 40 a 49 anos.

Figura 9 - Relação faixa etária com elemento de maior valor

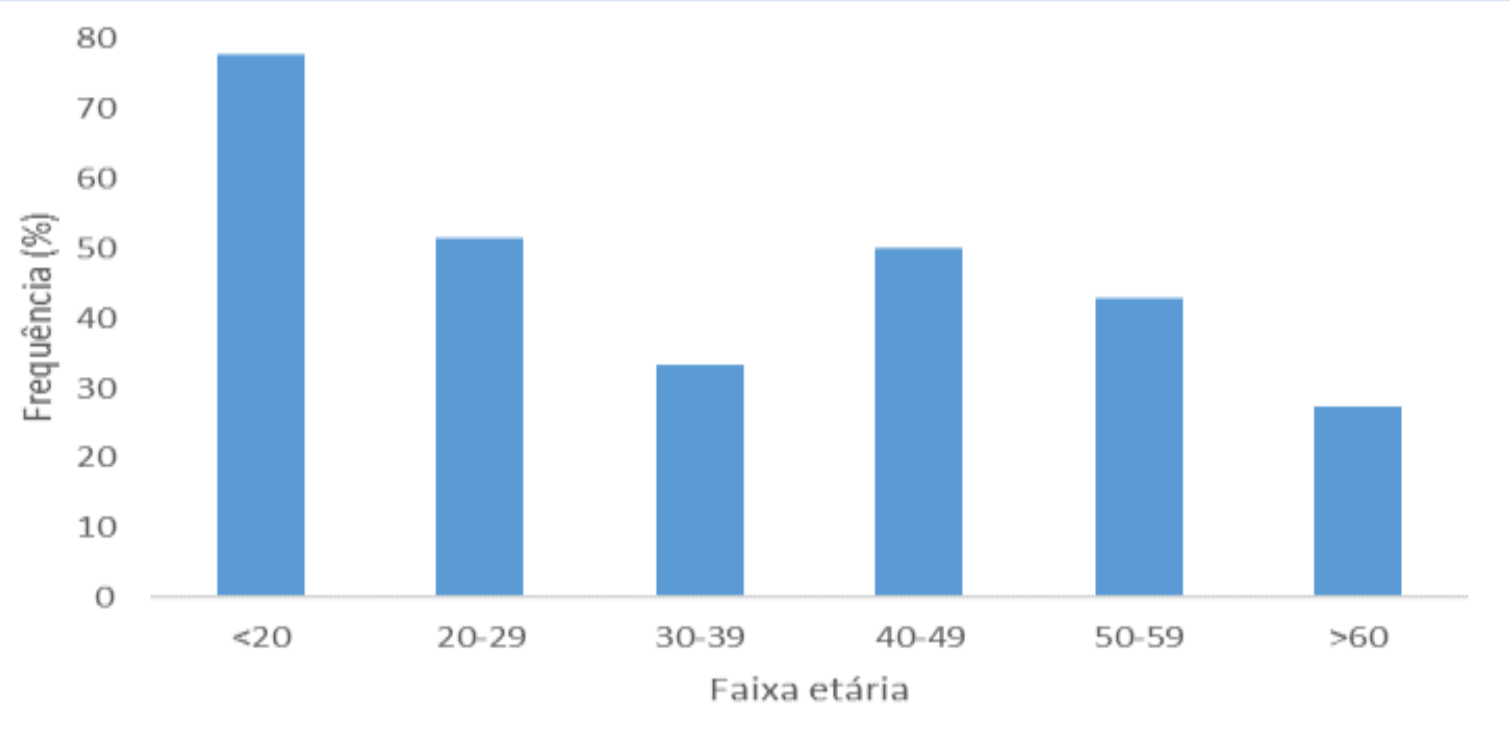

Fonte: os autores.

Segundo Neiman e Patrício (2010), cada indivíduo enxerga e interpreta o ambiente de acordo com suas experiências de vida. Se a população puder criar algum vínculo com as áreas protegidas, surgirá o sentimento de patrimônio comum e essas áreas serão mais bem conservadas.

A participação é essencial para a consolidação da unidade de conservação e ação que visa o envolvimento da sociedade é um dos elementos que devem ser incorporados em estratégias de gestão para que se atinja, da melhor maneira possível, os objetivos propostos pelas UCs (PRIMACK; RODRIGUES, 2001).

\section{CONCLUSÕES}

Os dados obtidos por meio das entrevistas mostraram que há pouco entendimento da população sobre questões relacionadas às unidades de conservação e ao Parque Estadual do Monge, mais especificamente.

A população demonstrou afeto pelo parque, principalmente pelo fato de se envolverem voluntariamente em ações para melhorias da unidade, porém nenhuma dessas ações está 
vinculada ao órgão gestor, mostrando uma falta de interação entre órgãos municipais, estaduais e comunidade.

Com isso, destaca-se a necessidade de uma maior e melhor interação entre órgãos e sociedade, objetivando uma maior eficácia na gestão e conservação da área protegida.

Com os resultados obtidos nesse trabalho é possível fazer uma análise e estabelecer planos de ação para o desenvolvimento de projetos que envolvam a comunidade no processo de gestão da unidade, de maneira a aperfeiçoar e estreitar o sentimento de pertencimento em relação a área, buscando a criação de um vínculo da população com o parque propiciando a sua conservação.

\section{REFERÊNCIAS}

BRASIL. Lei Federal no 9.985 de 18 de julho de 2000. Regulamenta o art. 225, § 1ำ, incisos, I, II, III e VII da Constituição Federal, institui o Sistema Nacional de Unidades da Conservação e dá outras providências. Disponível em:

<http://www.mma.gov.br/port/conama/legiabre.cfm?codlegi=322>. Acesso em: 10 set. de 2016.

FERNANDES, R. S. et al. Uso da percepção ambiental como instrumento de gestão em aplicações ligadas às áreas educacional, social e ambiental. In: ENCONTRO DA ASSOCIAÇÃO NACIONAL DE PÓS-GRADUAÇÃO E PESQUISA EM AMBIENTE E SOCIEDADE, 2., 2004, Indaiatuba. Anais... Belém: ANPPAS, 2004. p. 1-15. Disponível em: <http://www.anppas.org.br/encontro_anual/encontro2/GT/GT10/roosevelt_fernandes.pdf>. Acesso em: 10 set. de 2016.

HORNUNG, J. B. C. Análise das condições de uso do Parque Estadual do Monge, município da Lapa (PR). 2007. Dissertação (Mestrado em Geografia) - Universidade Federal do Paraná, Curitiba.

IAP. Instituto Ambiental do Paraná. Plano de manejo do Parque Estadual do Monge. Curitiba, 2002.

IPARDES. Instituto Paranaense de Desenvolvimento Econômico e Social. Caderno estatístico município de Lapa. Curitiba, 2016.

MARIN, A. A.; TORRES, O. H.; COMAR, V. A educação ambiental num contexto de complexidade do campo teórico da percepção. Interciência, Catanduva, v. 28, p. 616-619, 2003.

MARIN, A. A.; TORRES, O. H.; COMAR, V. Pesquisa em educação ambiental e percepção ambiental. Pesquisa em Educação Ambiental, Ribeirão Preto, v. 3, n. 1, p. 203-222, 2008.

MARIN, L. M. K. Contribuição ao zoneamento ambiental das bacias hidrográficas do Ribeirão do Calixto e Ribeirão Claro, na Lapa - Paraná. 2002. Dissertação (Mestrado em Geologia Ambiental) - Universidade Federal do Paraná, Curitiba.

MORAES, R. Análise de conteúdo. Revista Educação, Porto Alegre, v. 22, n. 37, p. 7-32, 1999. 
NEIMAN, Z.; PATRÍCIO, R. Ecoturismo e conservação dos recursos naturais. In: NEIMAN, Z; RABINOVICCI, A. Turismo e meio ambiente no Brasil. Barueri: Manole, 2010. p. 84104.

OKAMOTO, J. Percepção ambiental e comportamento: visão holística da percepção ambiental na arquitetura e na comunicação. São Paulo: Mackenzie, 2002.

PRIMACK, R. B.; RODRIGUES, E. Biologia da conservação. Rio de Janeiro: Planta, 2001.

SILVA, V. M.; SILVA, B. T. B. Percepção ambiental da comunidade do entorno do Parque Natural Municipal Barão de Mauá, município de Magé, RJ. Anais Uso Público em

Unidades de Conservação, Niterói, v. 1, n. 1, p. 200-210, 2013.

UNESCO. Rapport final du groupe d'experts sur le project 13: la perception de la quilité du milieu dans le programme sur I'homme et la biosphère. Paris, 1973. (Série des Repports du MAB, 9).

VILANOVA, S. R. F.; CHICHORRO, J. F.; ARRUDA, C. A. S. Disposição a pagar pelo uso de unidades de conservação urbanas: parque da cidade Mãe Bonifácia, Cuiabá - MT. Interações, Campo Grande, v. 11, n. 1, p. 43 - 53, 2010.

WHYTE, A. V. T. La perception de l'environment: lignes directrices méthodologiques pour les etudes sur le terrain. Paris, 1978. (Notes Techniques du MAB, 5).

Recebido: junho de 2017. Aceito: abril de 2018. 